\title{
Remedies to the Common Deficiencies Faced in Mivan Technology at Malin Rehabilitation
}

\author{
Prof. R. B. Bajare*, Shubham Deshmukh ${ }^{1}$, Ashwin Mahajan², \\ Roohi Karnataki ${ }^{3}$, Indrayani V. Patil ${ }^{4}$. \\ (Prof., Civil Department, Sinhgad Academy of Engineering, Kondhwa, Pune, Maharashtra) \\ ${ }_{1,2,3,4}$ (Students, Civil Department, Sinhgad Academy of Engineering, Kondhwa, Pune, Maharashtra)
}

\begin{abstract}
Mivan Technology is latest trend followed by developing and developed countries for mass housing projects. India being a developing country and shortage of houses for poor, this technology is nowadays widely used for government housing schemes and also by private construction companies. Mivan technology gives monolithic cellular structure with most minimum weight and the post failure damages get reduced considerably. The site selected for this project represents the rehabilitation of Malin village which was severely affected by landslide two years ago. Therefore the mivan formwork system is being used to construct the residential blocks for the villagers on site. But the problems like honeycombing, segregation and cracks due to shrinkage of concrete. In this project we have used the chemical admixture to increase the workabilty and compressive strength of concrete.
\end{abstract}

Keywords: Aluminium Formwork, Mivan Technology, Honey-combing, Cracks, Super Plasticizer.

\section{Introduction}

The system of aluminum formwork (MIVAN) has been used widely in the construction of residential units and mass housing projects. It is fast, simple, adaptable and cost - effective. It produces total quality work which requires minimum maintenance and when durability is the prime consideration. This system is most suitable for Indian condition as a tailor-made aluminum formwork for cast-in-situ fully concrete structure. In this system of formwork construction, cast - in - situ concrete wall and floor slabs cast monolithic provides the structural system in one continuous pour. Large room sized forms for walls and floors slabs are erected at site. These forms are made strong and sturdy, fabricated with accuracy and easy to handle. They can be used repeatedly for approximately 250 times. The concrete is produced in RMC batching plants under strict quality control and convey it to site with transit mixers. The frames for windows and door as well as ducts for services are placed in the form before concreting. Staircase flights, elevation panels, chajjas and jails etc. and other prefabricated items are also integrated into the structure.

On the Rehabilitation site at Malin village, 34 residential blocks having duplex accommodation of 1 room and 1 kitchen are being constructed by using Mivan formwork system. The purpose of choosing Mivan Technology over conventional method was the speedy construction, Monolithic homes in landslide prone zone. Strengthened structure in high rainfall intensity area.

Due to complexity of reinforcement and less thickness of wall, problems of honeycombing and shear cracks due to mass concreting are observed on sites and also, the problem was identified on other sites too. Therefore these problems needs to be tackled in effective way to ensure quality and safety of structure. These problems can be reduced by improving concrete characteristics.

\section{Problem Statement}

1) Cracks due to shrinkage of concrete are likely to appear.

2) Due to less thickness of wall honey-combing is commonly seen problem.

3) Due to complexity and high density of reinforcement at corners segregation occurs.

\section{Objectives}

1) To increase workability over long period for mass concreting work.

2) To increase compressive strength of concrete.

3) To reduce cracks due to shrinkage of concrete.

4) To reduce segregation and honey-combing effect at joints where dense reinforcement is provided 


\section{Methodology And Experimental Work}

To meet the objectives, we performed the compression test and slump cone/ flow table test on the concrete using admixture. Three grades (M25, M35 and M45) of concrete were used for experimental work. Nine different dosages of chemical admixture were applied. Minimum dosage was $0.8 \%$ of cementatious material and maximum dosage was $1.2 \%$. Dosages were applied by fixed interval of $0.05 \%$. Therefore, total 180 samples were tested for compression and workability of concrete. Samples were the standard sized concrete cubes $(15 \mathrm{~cm} \times 15 \mathrm{~cm} \times 15 \mathrm{~cm})$.

\section{Honey combing effect}

Honeycombing is the term used to describe areas of the surface that are coarse and stony. It may be caused by insufficient fine material in the mix, perhaps due to incorrect aggregate grading or poor mixing. This can be corrected by increasing the sand and cement content of the mix and by proper mixing, placing and compaction. Alternatively, honeycombing may be caused by leakage of grout or mortar fraction from the concrete at construction or formwork joints. The obvious solution here is to ensure that joints are well sealed and leak-free. Small, shallow areas of honeycombing are probably mainly cosmetic. However, deeper areas will lead to a local reduction in the protection to the reinforcement from the concrete cover and hence possibly durability problems in the future.

\section{Shrinkage of Concrete}

Shrinkage is defined as the contracting of a hardened concrete mixture due to the loss of capillary water. This shrinkage causes an increase in tensile stress, which may lead to cracking, internal warping, and external deflection, before the concrete is subjected to any kind of loading. All Portland cement concrete undergoes shrinkage or volume change as the concrete ages. The volume change in concrete is very important to the engineer in the design of a structure. Drying shrinkage can occur in slabs, beams, columns, bearing walls, pre-stressed members, tanks, and foundations.

\subsection{Details of structure.}

1) Area: 450 sq.ft (1 Block)

2) Number of floors. Ground floor (Single Storey Structure).

3) Wall Thickness: $100 \mathrm{~mm}$.

4) Slab Thickness: $125 \mathrm{~mm}$.

5) Reinforcement Size: $8 \mathrm{~mm}$.

6) Fine Aggregate: Crushed Sand.

7) Coarse Aggregate: $20 \mathrm{~mm}-30 \%, 12.5 \mathrm{~mm}-70 \%$

8) Mineral Admixture: Fly Ash.

9) Cement: OPC 53 Grade.

10) Chemical Admixture: CAC HyperFluid G+.

11) Concrete Grade: $M 25$.

12) Slump: $180-200 \mathrm{~mm}$ at time of pouring/pumping.

13) Type of concrete- Pumpable.

\subsection{Mix Design Calculations:}

Specifications of Admixture:

Manufacturer: CAC Group Co.Ltd.

Name: CAC HyperFluid G+

Base Chemical: PolyCarboxylic Ether (PC)

Appearance: Brown

Form: Liquid.

Sp. Gravity: $1.08 \pm 0.02$

$\mathrm{P}^{\mathrm{H}}:$ 6-8

Recommended Dosage: $0.8 \%-1.2 \%$

Mix Design Specification

Grade Designations: M25, M35, M45.

Water reduction for Admixture: $20 \%$

Type of cement: OPC 53

Substitute for cement: Fly ash @ 25\% 
4.3 Test Results

Mix Design of M25:

Conventional: 1: 1.83:2.21

With Admixture: 1: 2.61:3.16

M25 with Admixture:

\begin{tabular}{|c|c|c|}
\hline \multicolumn{3}{|c|}{ Compressive Strength $\left(\mathbf{N} / \mathbf{m m}^{2}\right)$} \\
\hline Dosage \% & $\mathbf{7 ~ d a y s}$ & 28 days \\
\hline 0.8 & 19.44 & 27.64 \\
\hline 0.85 & 19.86 & 28.67 \\
\hline 0.9 & 20.63 & 30.40 \\
\hline 0.95 & 20.87 & 31.78 \\
\hline 1 & 21.76 & 33.73 \\
\hline 1.05 & 20.86 & 31.15 \\
\hline 1.1 & 20.29 & 29.93 \\
\hline 1.15 & 19.55 & 28.64 \\
\hline 1.2 & 18.45 & 27.49 \\
\hline
\end{tabular}

M25 (Conventional)

\begin{tabular}{|c|c|}
\hline \multicolumn{2}{|c|}{ Compressive Strength $\left(\mathbf{N} / \mathbf{m m}^{2}\right)$} \\
\hline $\mathbf{7}$ days & $\mathbf{2 8}$ days \\
\hline 18.23 & 26.33 \\
\hline
\end{tabular}

\section{Mix Design of M35}

Conventional: 1:1.56:1.95

With Admixture: 1: 2.24:2.81

M35 with Admixture:

\begin{tabular}{|c|c|c|}
\hline \multicolumn{3}{|c|}{ Compressive Strength $\left(\mathbf{N} / \mathbf{m m}^{\mathbf{2}}\right)$} \\
\hline Dosage \% & $\mathbf{7}$ days & $\mathbf{2 8}$ days \\
\hline 0.8 & 25.91 & 37.09 \\
\hline 0.85 & 26.86 & 38.65 \\
\hline 0.9 & 27.20 & 41.35 \\
\hline 0.95 & 29.44 & 43.98 \\
\hline 1 & 28.40 & 41.87 \\
\hline 1.05 & 26.95 & 40.94 \\
\hline 1.1 & 25.85 & 38.73 \\
\hline 1.15 & 24.09 & 36.76 \\
\hline 1.2 & 22.13 & 36.08 \\
\hline
\end{tabular}

M35 (Conventional):

\begin{tabular}{|c|c|}
\hline \multicolumn{2}{|c|}{ Compressive Strength $\left(\mathbf{N} / \mathbf{m m}^{\mathbf{2}}\right)$} \\
\hline $\mathbf{7}$ days & $\mathbf{2 8}$ days \\
\hline 25.58 & 36.68 \\
\hline
\end{tabular}

M2S DOSAGE Vs. STRENGTH

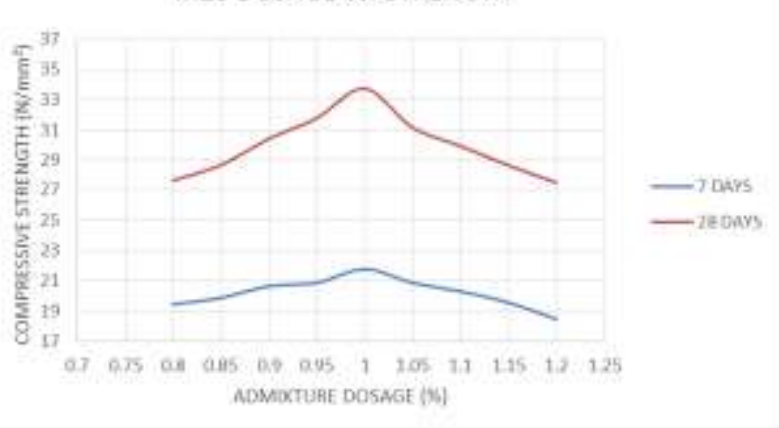

CONVENTIONAL CONC. VS. ADMIXTURED CONC.(M25)
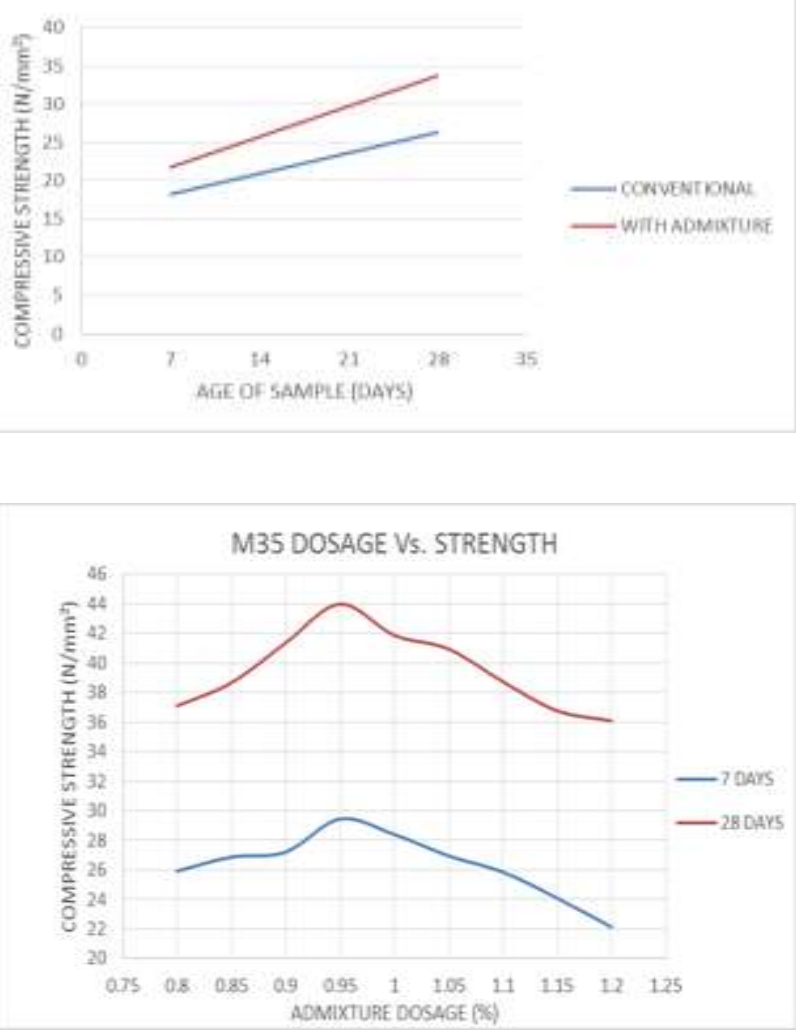

CONVENTIONAL CONC, VS. ADMIXTURED CONC.(M3S)

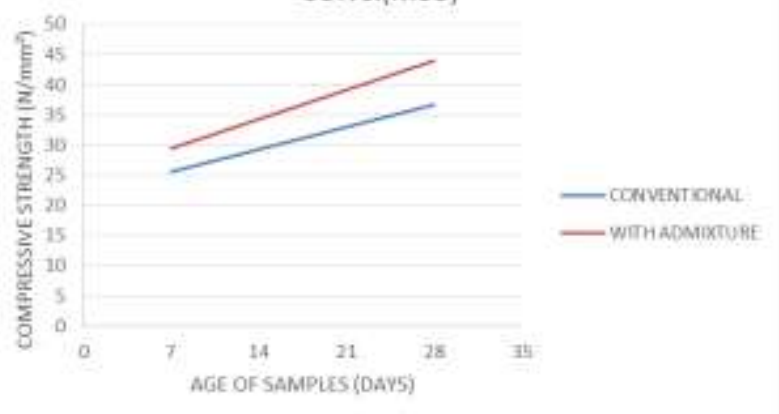




\section{Mix Design of M45}

Conventional: 1:1.30:1.69

With Admixture: 1:1.90:2.47

M45 with Admixture:

\begin{tabular}{|c|c|c|}
\hline \multicolumn{3}{|c|}{ Compressive Strength $\left(\mathbf{N} / \mathbf{m m}^{2}\right)$} \\
\hline Dosage \% & 7 days & 28 days \\
\hline 0.8 & 34.50 & 50.88 \\
\hline 0.85 & 35.42 & 54.69 \\
\hline 0.9 & 34.64 & 52.46 \\
\hline 0.95 & 33.53 & 51.15 \\
\hline 1 & 32.03 & 50.23 \\
\hline 1.05 & 30.62 & 48.79 \\
\hline 1.1 & 29.85 & 47.44 \\
\hline 1.15 & 28.13 & 46.45 \\
\hline 1.2 & 27.50 & 45.40 \\
\hline
\end{tabular}

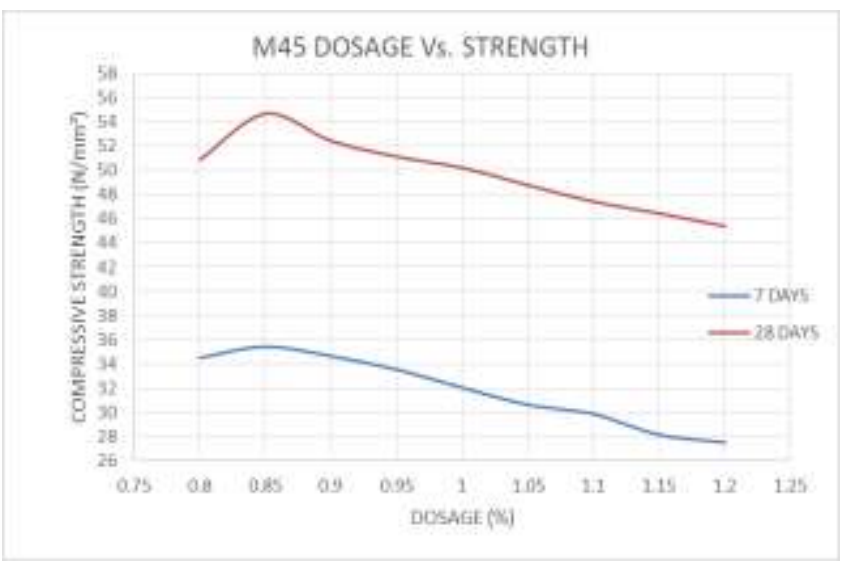

M45 (Conventional):

\begin{tabular}{|c|c|}
\hline \multicolumn{2}{|c|}{ Compressive Strength $\left(\mathbf{N} / \mathbf{m m}^{2}\right)$} \\
\hline $\mathbf{7}$ days & $\mathbf{2 8}$ days \\
\hline 31.43 & 46.42 \\
\hline
\end{tabular}

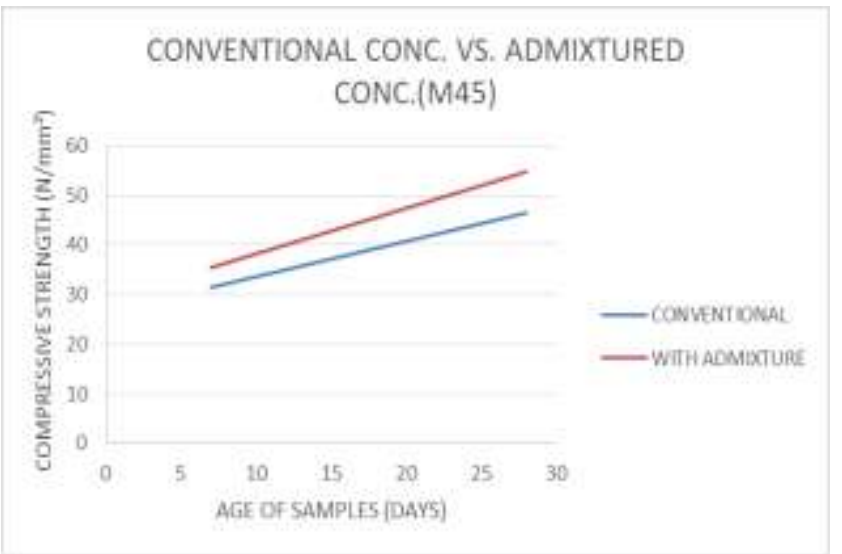

\section{Conclusion}

As the results shows, Compressive strength of concrete for all grades (M25, M35, and M45) is increased by $15 \%$ to $20 \%$ over the conventional concrete. Compressive strength is the important parameter and hence it is concluded that using admixture compressive strength is increased. Compressive strength is dependent on the dosage of chemical admixture too.

As the graphs shows, Compressive strength increases as the dosage is increased but after some point strength starts falling proving the admixture ineffective. The dosage at which the compressive strength is maximum just before it starts falling down is called optimum dosage for that designation. At this point, the workability is also can be considered as optimum because by increasing dosage workability goes on increasing but after optimum dosage mix is segregated. Optimum dosage also depends on the material properties, mix designation. As we can see we have obtained these points at $0.85 \%, 0.95 \%$ and $1 \%$ for M45, M35 and M25 respectively. We had used $12.5 \mathrm{~mm}$ coarse aggregate in greater portion (70\%) and $20 \mathrm{~mm}$ in shorter portion $(30 \%)$. Therefore, with increased workability and reduced aggregate size concrete will occupy congested place between reinforcement and formwork effortlessly.

On site only M25 grade was used as the structure was single storey building. But we have tested the M35 and M45 also because the results will be beneficial to multi storey building which uses the M45 and M35 commonly and in a combination. Thus, this project concludes that the problem of honeycombing will be reduced and the strength is increased by use of admixture if applied in proper dosage. Also the water can be reduced by $20 \%$ or more by using super-plasticizer. This will reduce the heat of hydration and hence the shrinking and cracks due to shrinkage will be eliminated. Crack less and Honeycomb free surface will resist the harsh weathering. Also it will provide smoother surface finish and overall better quality of construction.

\section{Acknowledgement}

This project is now on completed just because of the following people to whom which we really thanks from depth of our heart. I feel fortune having Prof. R. B. Bajare sir as our project guide. We would like to thank HOD Prof. R. R. Sorate sir for his continuous Encouragement and support. The acknowledgement will be incomplete if we don't record sense of gratitude to our principal Dr. K. P. Patil sir and last but not the least we would like to thank to our college, who were Associated with us and helped us in preparing our report. The 
report Named "Remedies to the common deficiencies faced in MIVAN Technology at Malin rehabilitation" would not been possible without the extensive support of people who were directly or indirectly involved in its successful manner. We are thankful to Ultra Promoters and Developers Pvt., Ltd. for providing sponsorship for the experimental work require for project. We are thankful to Mrs. Sonal Lakade Madam, Technical Head, RMC Ready Mix India Pvt., Ltd. for providing us with testing equipment and materials.

We are thankful to Mr. Nilesh Bajare Sir, Project In charge, Malin Rehabilitation Site. For the all data and useful information required about the actual site. Finally, we would like to thanks our college Sinhgad Academy of Engineering where the documentation and Report part is done. We are grateful towards Department of Civil Engineering, SAE, Kondhwa.

\section{References}

[1]. Miss. Patil Dhanashri Suryakant , Prof. DeSAi D B “EMERGING TRENDS IN FormWORK - CoSt ANALYSIS \& EFFECTIVENESS OF MIVAN FORMWORK OVER THE CONVENTIONAL FORMWORK” (IOSR JOURNAL OF MECHANICAL AND CIVIL ENGINEERING (IOSR-JMCE) ISSN: 2278-1684, PP: 27-30 WWW.IOSRJOURNALS.ORG)

[2]. Dr. M. N. Bajad, Pawan S. Khandelwal, Avihv Vyavhare. “Comparative study of formwork” (ijoer, vol. 4., issue.32016 may-june) issn: 2321-7758 building construction)

[3]. Prof. C. S. Chavan, Lalit V. Rathod, Vishwas L. Nachare, Atul, B. Suryawanshi. "Cost Effective House by Using Various Construction Techniques and Materials" (IJOAR Volume : 4 | Issue : 4 | Apr 2014 | ISSN - 2249-555X)

[4]. Mr. Shankar Bimal Banerjee, Mr. Pawan Dilip Barhate, Mr. Vipul Pradip Jaiswal. "Mivan Technology”(.International journal of innovations in engineering research and technology [ijiert] Issn: 2394-3696 Volume 2, issue 3 march2015)

[5]. Umang Patel, Bhupendra M Marvadi, Ninjal M. Parekh. "Comparative Studies of Construction Techniques (Conventional Technique Vs Aluminium Formwork Techniques) ISSN: 0975 - 6744| NOV 14 TO OCT 15 | Volume 3, Issue 2

[6]. Prof. U. J. Phatak Prof.C.S.Chavan, Lalit V. Rathod. "Cost Effective House by Using Various Construction Techniques and Materials"(IJOAR Volume : $4 \mid$ Issue : 4 | Apr $2014 \mid$ ISSN - 2249-555X)

[7]. Divyang Solanki, Rinni Shah, Noopur Shah. "Benefits of Mascon Construction System in Economical Area"(IJSRD - International Journal for Scientific Research \& Development| Vol. 1, Issue 3, 2013 | ISSN (online): 2321-0613)

[8]. Rohan D More, Dr. Y. S. Patil. "Comparative Analysis with Mivan Formwork \& Concrewall Structure”. International Journal of Current Trends in Engineering \& Research (IJCTER) (e-ISSN 2455-1392 Volume 2 Issue 2, February 2016 pp. 132-135)

[9]. http://www.architectjaved.com/mivan-formwork

[10]. http://www.mivan.com/modular/Mivan_Modular.pdf 